\title{
Transitioning Health Educators to Clinical Settings
}

\author{
Mary M. Hoke ${ }^{1}$, Theresa L. Byrd ${ }^{2}$, and Nell H. Gottlieb ${ }^{3}$ \\ ${ }^{1}$ New Mexico State University \\ ${ }^{2}$ University of Texas at El Paso \\ ${ }^{3}$ University of Texas at Austin
}

\begin{abstract}
Objective: A support model consisting of a local health educators' network, a technical assistance team with academic and practice experts, and an evolving sequence of professional continuing education activities supported health educators transitioning from community or school health education sites to health care sites as part of the Clinic Health Education and Life Style Promotion Project (Clinic HELP) designed to increase health education options for individuals within the Paso del Norte Region of the United States-Mexico Border. Methods: Focus groups, interviews and surveys were used to evaluate intervention activities designed to assist in the transition. Results/Conclusions: Lack of familiarity with health care settings and role delineation were identified as barriers while "expert" sounding boards, professional development activities, and advanced education assisted in the transition. Use of the professional network was less than anticipated. Practice Implications: Based on the Clinic HELP experience, recommendations are provided for professional education and support for health educators within clinical practice settings.
\end{abstract}

(c) 2007 Californian Journal of Health Promotion. All rights reserved.

Keywords: Health education, clinic-based health promotion, competencies, health educators

Nationally, health education professional preparation programs continue to structure training by practice setting (McKenzie, 2004), with an emphasis on school and community settings being common. In addition, obtaining employment for the entry-level health educator involves acquiring additional skills that may be desired by an employer (Lindsay, Hanks, Neiger, \& Barnes, 2000). The purpose of this article is to report the evaluate findings of the three-pronged model (networking, technical assistance, training) used to facilitate the transition of health educators from community to clinical settings.

The Clinic Health Education and Lifestyle Promotion (HELP) Initiative, funded by the Paso del Norte Health Foundation (PDNHF), was a program designed to maximize health outcomes among medically-indigent residents in far west Texas and southern New Mexico (Paso del Norte Region) through the provision of health education and health promotion activities at community health clinic sites. Building competency for the health educators to operate in a clinical setting was an imperative challenge given the emphasis on community and school based health education of local health education preparation programs and the lack of health education resources directed at lifestyle change and risk reduction found within the primary care sites that served as the central sources of accurate health information for large numbers of uninsured (Condon, Pauli, Price, Fry, Kaigh \& Kaigh, 1997) in the region.

\section{Project Description}

The Clinic HELP goal was to provide residents in the service area with access to effective health education and health promotion services at their primary health care site. Ten individuals were hired to function as health educators within the clinics involved in the initiative. Of these, four were baccalaureate prepared health educators, two were graduate prepared health educators and the remaining individuals were from a variety of 
disciplines to include social work and nursing. (See Hoke, Byrd, Kelly, Brandon \& Lang, 2002 for a full description of the health educators). Six assumptions were made by the PDNHF when this initiative was started: 1) the available local pool of health educators with expertise in clinical services would be limited; 2) a structured support system would be necessary; 3) the practical wisdom of clinical practice and the theoretical and research capacities of academic institutions should be linked; 4) cultural appropriateness and bilingual communication would be fundamental; 5) local needs should guide project interventions at each site; and 6) program planning must include attention to sustainability.

Often as the sole health educator in a clinical site, a practitioner may feel isolated and have few opportunities to increase professional competency. In this project two mechanisms for increasing professional social support were developed. A small network of the ten Clinic HELP health educators participated in monthly training and work sessions, annual sharing meetings, and retreats. In addition, a larger network for any interested health educators in the region provided bimonthly meetings for social support, training, and information exchange.

Meeting every two months, the network offered continuing education units, social support, and professional growth opportunities. All Clinic HELP health educators $(n=10)$ attended most meetings, along with other health educators (range $=1-20$ ) from a variety of government, notfor-profit, and private agencies. Officers for the network were elected annually. The officers planned the educational activities for the year plus coordinated an annual awards luncheon to recognize a local health educator. This network formed the base for the Paso del Norte Society for Public Health Education chapter, established in 2001.

A Technical Assistance Team (TAT) was established to provide ongoing support to the ten Clinic HELP health educators. TAT members included the program officer from the Foundation, the project director from a College of Health Science at a local university, a behavioral scientist/public health nurse from a local school of public health, a health education director from the New Mexico State Department of Health, and a health education department chair from a regional university. The program officer and project director provided support to all the health educators while other TAT members mentored specific health educators. Technical assistance from the contracted TAT members was both active and responsive. TAT members performed periodic announced site visits, reviewed progress reports, and responded to particular needs unique to a clinic's program.

To supplement the individual mentoring provided by the TAT, an evolving sequence of professional continuing education activities on various topics was developed (see Table 1). Training topics during years one and two, program planning and evaluation, were primarily selected by the TAT. Those in years three and four, clinical content and institutionalization were selected by the health educators using nominal group process, which they had learned during training. Presented by the TAT members and outside consultants, all training activities and professional continuing education credit were offered at no cost to Clinic HELP health educators. To further advance professional networking and competencies related to their scope of work, professional development funds were allocated upon request. These funds helped the health educators attend national conventions and become members of related organizations.

\section{Methods}

\section{Data Collection and Analysis}

To evaluate intervention activities to increase health educator competence, data were collected using three different techniques, analyzed, and then triangulated. The data collection techniques were focus groups, interviews, and surveys. This study was approved by the Committee for the Protection of Human Subjects at the University of Texas at El Paso. 
Table 1

Selected List of Clinic HELP Training Topics

\begin{tabular}{|c|c|c|}
\hline Year & $\begin{array}{c}\text { Continuing Professional } \\
\text { Education Theme }\end{array}$ & Training Topics \\
\hline One & Program Planning & $\begin{array}{l}\text { - Health Promotion Theory } \\
\text { - PRECEDE/PROCEED } \\
\text { - Cost effectiveness of health promotion } \\
\text { - Health promotion and cost analysis } \\
\text { - Application of the trans-theoretical model in program planning }\end{array}$ \\
\hline Two & Evaluation & $\begin{array}{l}\text { - } \text { CDC Synergy } \\
\text { - Program evaluation } \\
\text { - Participatory evaluation } \\
\text { - Putting evaluation into practice } \\
\text { - } \text { PRECEDE/PROCEED approach to evaluation } \\
\end{array}$ \\
\hline Three & Clinical Content & $\begin{array}{l}\text { - Asthma control } \\
\text { - Prescriptive physical activity } \\
\text { - Environmental health } \\
\text { - Diabetes }\end{array}$ \\
\hline Four & Institutionalization & $\begin{array}{l}\text { - Grant writing retreat } \\
\text { - Intervention Mapping } \\
\text { - Use of statistics } \\
\text { - Use of the media } \\
\text { - Legal issues in health care }\end{array}$ \\
\hline
\end{tabular}

Four focus groups were conducted in the late summer and early fall of 2000 by an experienced moderator from outside the area. In the first focus group, data were collected from all members of the TAT $(\mathrm{N}=5)$. The second focus group was held for administrative directors $(\mathrm{N}=9)$. Two additional focus groups were comprised of the health educators $(\mathrm{N}=4, \mathrm{~N}=5)$. Private meeting rooms were secured so as to provide neutral sites. The focus group discussions were recorded and then transcribed to help uphold accuracy and anonymity. Thematic analysis was conducted and the interpreted narrative was returned to focus group members for their review and affirmation of the interpretations drawn from the narratives.

Individual clinic site visits and interviews were conducted with health educators $(\mathrm{N}=10)$. Additional interviews were completed with the executive directors $(\mathrm{N}=9)$ and with first-line supervisors of health educators, various clinicians, clinical peers, and community health workers who worked with the health educator. These included 10 physicians, two nurse practitioners, one physician assistant, 13 nurses, six lay health workers, four social workers, and 10 additional administrative and allied health personnel. Trained project research assistants conducted the guided interviews. The interviews were tape recorded for later transcription and thematic analysis.

Using a social network data collection form, each health educator rated all other health educators and TAT members. Ratings included duration of acquaintance (months), frequency of contact (six categories from less than once a month to daily or almost every day), strength of the personal relationship (How likely would you be to contact this person for personal advice? Not likely at all, somewhat likely, very likely), strength of the professional relationship (How likely would you be to contact this person for professional advice? Not likely at all, somewhat likely, very likely), association outside of work 
(yes frequently, yes occasionally, no), and overall importance of the relationship (4-point scale from not important at all to very important).

Seven training formats were rated from not helpful (1) to extremely helpful (4) by the health educators for their degree of helpfulness in enhancing individual skills. To assess the perceived value of training, the health educators indicated whether, should the training activities be optional rather than required, they would still plan to attend each of the activities. Ratings for this assessment ranged from absolutely not attend (1) to absolutely attend (4).

A delineation of competencies for the Certified Health Education Specialist (National Commission for Health Education Credentialing, 1999) was used as the basis for an evaluatordesigned survey tool. The National Committee for Certification of Health Educators, Inc. (1985) has delineated a total of 81 tasks, nested within 27 essential competencies, which are themselves nested within a statement of seven (7) responsibilities which are considered the essential functions of the community health educator role. Each health educator conducted a self-assessment and each supervisor also independently rated the performance of the health educator on each of these elements, ranging from not competent (1) to very competent (4). Each respondent assigned two time-based ratings: a retrospective assessment of performance upon entry into practice in the agency setting and an assessment of current (year three) performance. Average rating scores were computed for each competency for each of the two time periods and for each of the evaluators (health educator and first line supervisors). Differences between the selfassessment and supervisor ratings were also computed across all competencies.

\section{Results and Discussion Barriers}

Two barriers specific to transition to health education practice in a clinical setting were identified in the focus groups and interviews. The first barrier was a perception that the health educators may not have been familiar with constraints imposed by working within a medical system. For example, the health educators were not fully aware of quality assurance and documentation procedures. Second, a lack of clarity about role delineation and definition proved to be a barrier. Uncertainty about how the medical professionals, social workers, lay health workers, and other existing staff should articulate with the health educator, for which no existing position description existed in eight of the nine clinics, served to obstruct effective delivery of health education services.

\section{Technical Assistance Team}

TAT members identified their own role as a proactive one in assisting the individual health educators to find their own ways and means of proceeding. One TAT respondent said that the role was to: "work with...directors and the health educators to find out what's going to work...versus having a preordained agenda.” In the focus groups, health educators reported that the TAT was extremely supportive, specifically in health education program development and evaluation and in coordination of ongoing training. The TAT was described by one participant as a "safe sounding board".

According to the network analysis, the TAT members reported interacting with their assigned clinic health educator rather than with all health educators. The director, on the other hand, was perceived by all health educators to be a resource. The TAT members provided individualized technical assistance based on the needs of the individual health educators and the context in which they worked.

\section{Relationships}

We examined the relationships among members of the network of Clinic HELP health educators and the TAT. Analysis of data derived from the network analysis form is reported in terms of the sum of ratings assigned by any single individual to all others in the personal network. The duration of network relationships ranged from five (5) months to five (5) years. The shorterterm relationships correlated with the length of time that some individuals had been participants in the Clinic HELP projects. The longer-term 
relationships were attributed to familiarity with each other from professional preparation. The frequency of interaction between network partners was, for the large majority, less than once per month. When professional advice was needed, approximately one-half of the respondents reported they were not at all likely to seek that advice from the other Clinic HELP health educators, and the remainder were almost equally somewhat (22\%) or very (24\%) likely to contact them. When advice was needed on a personal matter, outside of work hours, respondents were even less likely to contact the other health educators (79\% were not likely at all to do so). Respondents were also, in the majority, not likely to associate with these network partners outside of work on a social basis. Nevertheless, the majority rated these relationships as very important or somewhat important to them.

When a respondent indicated an intention to contact another network partner, the contact was more likely to be with a TAT member than with another health educator. Seven individuals did identify at least one other health educator whom they were very likely to contact and one individual identified two others whom they were somewhat likely to contact. When an individual was identified, there was also endorsement that the relationship was somewhat or very important to them.
This under-utilization of the network may reflect the distance between health educators at their various worksites and also the fact that several project participants were newer employees in their respective positions and had not, therefore, had opportunity to fully build these relationships.

\section{Group Professional Development}

Seven professional development approaches were rated by the health educators for their degree of helpfulness in enhancing individual skills, for perceived value and whether they would attend even if not required to do so. The formats varied by participation restrictiveness, length of training, use of local or outside experts, geographic location, and whether they were open to non-Clinic HELP health educators. The highest ratings were assigned to periodic trainings and retreats and the lowest ratings were assigned to the HELP network meetings (See Table 2). The HELP network meetings were of shorter duration (1-2 hours), while the other activities ranged from 6-24 hours. Because the majority of health educators lived in El Paso, Las Cruces, which is about 45 miles away, may have been seen as less convenient. These findings support the high value placed by these health educators on continuing in-depth professional education. Supervisors also valued training for their health educators, with ratings of perceived helpfulness ranging from 3.5 to 3.8 across all formats.

Table 2

Satisfaction with Training Activities

\begin{tabular}{|l|c|c|}
\hline \multicolumn{1}{|c|}{ Training Format } & $\begin{array}{c}\text { Helpfulness } \\
\text { Mean (SD) }\end{array}$ & $\begin{array}{c}\text { Perceived Value } \\
\text { Mean (SD) }\end{array}$ \\
\hline Periodic training by outside resources $^{\mathrm{a}, \mathrm{b}}$ & $3.8(0.4)$ & $3.7(0.5)$ \\
\hline Retreats $^{\mathrm{a}}$ & $3.6(.7)$ & $3.8(0.7)$ \\
\hline Monthly training and work sessions $^{\mathrm{a}}$ & $3.5(0.7)$ & $3.4(0.7)$ \\
\hline Periodic training by TAT members $^{\mathrm{a}, \mathrm{b}}$ & $3.4(0.5)$ & $3.7(0.5)$ \\
\hline Annual sharing meetings $^{\mathrm{a}}$ & $3.3(0.7)$ & $3.5(0.7)$ \\
\hline HELP Network meetings (El Paso) $^{\mathrm{a}, \mathrm{b}}$ & $3.1(1.0)$ & $3.1(1.0)$ \\
\hline HELP Network meetings (Las Cruces) $^{\mathrm{a}, \mathrm{b}}$ & $2.6(1.3)$ & $2.5(1.3)$ \\
\hline
\end{tabular}

a restricted to Clinic HELP health educators; ${ }^{b}$ open to all area health educators; *1= not helpful to

$5=$ extremely helpful; **1= absolutely not attend to 4 absolutely attend 


\section{Competencies}

Average rating scores across the 10 health educators were computed for each competency for each of two time periods (Years 1 and 3) and for each of the evaluators (HE and first line supervisors). Differences between the selfassessment and supervisor ratings were also computed, across all competencies. As seen in Table 3, the ratings reflected a consistent pattern. Individual growth was evident over time, both as self-assessed and, to a much lesser extent, as externally evaluated. The average initial assessment by health educators was 2.3 and by administrators, 3.4. The average current assessments were 3.4 and 3.5 by health educators and administrators, respectively. The difference in baseline scores between the health educators and their supervisors was striking. It may be that health educators were more discerning of their competence than the supervisors. For many supervisors, this was their first experience with a professional health educator and the competencies of the field.

Evaluating programs was the lowest rated competency at initial employment and, with communication of needs, showed the most improvement. Health education theory and health promotion planning using PRECEDE/ PROCEED were key training topics in year one, while program evaluation was stressed in year two.

Table 3

Health Educator's Self and Supervisory Competency Ratings at Initial Hire and During Year Three ${ }^{\mathrm{a}}$

\begin{tabular}{lcccc}
\hline & \multicolumn{2}{c}{ Health Educator } & \multicolumn{2}{c}{ Supervisor } \\
\hline & $\begin{array}{c}\text { Initial } \\
\text { employment* } \\
\boldsymbol{M}(\boldsymbol{S D})\end{array}$ & $\begin{array}{c}\text { Late } \\
\text { employment* }\end{array}$ & $\begin{array}{c}\text { Initial } \\
\text { employment* }\end{array}$ & $\begin{array}{c}\text { Late } \\
\text { employment* }\end{array}$ \\
& $2.6(1.0)$ & $3.5(0.7)$ & $3.3(0.6)$ & $\boldsymbol{M}$ (SD) \\
Responsibility I: Assessing needs & $2.7(0.8)$ & $3.5(0.6)$ & $3.2(0.7)$ & $3.5(0.6)$ \\
Responsibility II: Plans programs & $2.7(0.8)$ & $3.5(0.6)$ & $3.3(0.7)$ & $3.7(0.4)$ \\
Responsibility III: Implements programs & $2.1(0.9)$ & $3.2(0.6)$ & $3.3(0.6)$ & $3.6(0.4)$ \\
Responsibility IV: Evaluates effectiveness & $2.4(1.0)$ & $3.4(0.6)$ & $3.4(0.6)$ & $3.7(0.4)$ \\
Responsibility V: Coordinates services & $2.4(1.0)$ & $3.4(0.6)$ & $3.5(0.6)$ & $3.7(0.4)$ \\
Responsibility VI: Acts as resource & $2.3(0.9)$ & $3.4(0.7)$ & $3.3(0.6)$ & $3.5(0.5)$ \\
Responsibility VII: Communicates needs &
\end{tabular}

${ }^{\mathrm{a}}$ Retrospective Data; *Scale 1= not competent to 4= very competent

\section{Professional Preparation}

Both health educators and clinic administrators indicated that certification added value to the health educator role. This may be especially true of clinical settings, as licensure is the norm for health care professionals. However, despite calls for emphasizing common competencies in all practice settings, health education professional preparation and continuing education must be responsive to the unique characteristics of various practice settings. In this project, administrators, more than health educators, thought that a period of internship ("real world learning") should follow basic preparation. Administrators also noted that health educators should be very knowledgeable about their communities. Health educators indicated that when working in clinical settings, the important skills that should be added to their basic competencies should include information about chronic diseases, administration and management skills, and grantsmanship. Assertiveness and communication skills were personal attributes that were also valued by the heath educators, as facilitating factors for role implementation.

The consensus among TAT members was that clinical practice setting positions should not be filled by entry level bachelors-prepared health educators. As one TAT member said, “...we learned that at (agency $\mathrm{x}$ ) when we hired two non-experienced undergraduate trained people and it was awful for them and the clinic”. At 
another clinic, another TAT member recalled the health educator "...more than once coming up and basically saying, 'I'm not sure what I'm supposed to be doing'”. In recognition of the need to further define the health educator role, the National Commission for Health Education Credentialing has expanded the areas of responsibility and competencies for graduate level health educators (Barnes, Neiger, Mondragon, Hanks, \& Brandon, 2002).

\section{Practice Implications}

The health care clinic is a viable practice setting for health educators. However, professional preparation and continuing education must be responsive to the unique characteristics of this practice setting (Barnes et al., 2002; McKenzie, 2004). Curriculum content to meet this need would likely include patient confidentiality, scope and practice of various health care providers, and legal and ethical issues in health care, as well as health issues related to specific disease states. One method of accomplishing this would be the development of interdisciplinary education programs, especially in those institutions where multiple health professional programs exist. Health educators desiring to work in clinical settings should be encouraged to obtain masters level education and general health educator certification and, as it becomes available, specialist level health educator certification.

A clear understanding of the health educator role by the employer as well as the health educator facilitates the successful transition from community to clinical practice. Employers should be encouraged to use national competencies in developing health educator position descriptions and performance standards. In addition, other professionals in the clinic should be educated about the role of health educators so that they can more effectively work as part of a multidisciplinary team.

Entry level health educators in clinical settings, with limited experience, must have additional support. One source of support may be networking with other health educators through local professional organizations. These should be encouraged to asses the need for, and provide in-depth continuing education. A second source might include contracting with local universities for technical assistance, facilitating the linkage between academia and practice. Training specific to the clinic site, such as quality assurance, making referrals, and Joint Accreditation on Healthcare Organizations requirements, can be obtained through interdisciplinary professional development activities in one's home agency or through professional organizations. Informal interdisciplinary networks provide a source of information, and should be fostered.

The Clinic HELP initiative demonstrates that the successful transition of health educators from a community setting to a clinical setting is enabled by a support system, individualized technical assistance, and ongoing professional education and training. The evaluation of this multidimensional professional development education approach adds to the sparse literature in this area (Rivers, Aggleton, \& Whitty, 1998).

\section{References}

Barnes, M. D., Neiger, B. L., Mondragon, D., Hanks, W. A., \& Brandon, J. E. (2002). Expanded health education roles in managed care: Relationships between CHES, HEDIS, and NCQA. Health Promotion Practice, 3(1), 43-49.

Condon, K., Pauli, A., Price, V., Fry, B., Kaigh, W., \& Kaigh, G. (1997). El Paso health report. Paso del Norte Health Foundation, El Paso, TX.

Hoke, M. M., Byrd, T. L., Kelly, M. P., Brandon, J. E., \& Lang, P. (2002). The Clinic HELP initiative: Promoting health education in primary care clinics. Health Promotion Practice, 3, 477-484.

Lindsay, G. A., Hanks, W. A., Neiger, B. L., \& Barnes, M. D. (2000). Enhancing student employability: Perceptions of faculty advisors and community health practitioners. Journal of Health Education, $31,10-13$.

McKenzie, J. F. (2004). Professional preparation: Is a generic health educator really possible? American Journal of Health Education, 35, 16-18. 
National Commission for Health Education Credentialing. American Association for Health Education, and Society for Public Health Education. (1999). A competency-based framework for graduate level health educators. Allentown, PA. Author.

National Task for on the Preparation and Practice of Health Educators, Inc. (1985). A framework for the development of competency-based curricula for entry level health educators. New York: Author.

Rivers, K., Aggleton, P., \& Whitty, G. (1998). Professional preparation and development for health promotion: A review of the literature. Health Education Journal, 57, 254-262.

\section{Acknowledgements}

We would like to thank the Paso del Norte Health Foundation for their support of this project.

A significant portion of the work by M. H. Hoke was accomplished while at the School of Nursing, University of Texas at El Paso.

\section{Author Information}

Mary M. Hoke, Ph.D., RN-BC, APRN-BC*

Department Head and Associate Professor

New Mexico State University

School of Nursing MSC 3185

PO Box 30001

Las Cruces, NM 88003-8001

Ph.: 505-646-7449

Fax.: 505-646-4356

E-Mail: mhoke@nmsu.edu

Theresa L. Byrd, Dr.P.H.

Associate Professor

University of Texas School of Public Health

El Paso Campus

Nell H. Gottlieb, Ph.D.

Professor

University of Texas at Austin

Department of Kinesiology and Health Education

* corresponding author 